\title{
Buccodental side effects of sunitinib in patients with metastatic renal cell carcinoma
}

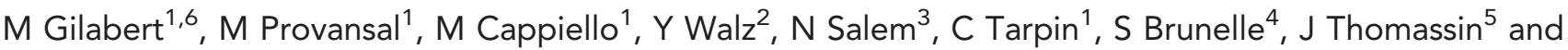 \\ G Gravis ${ }^{\star}, 1,6$
}

${ }^{1}$ Department of Medical Oncology, Paoli-Calmettes Institute, 232 Bd Sainte Marguerite, Marseille 13009, France; ${ }^{2}$ Department of Surgery, Paoli-Calmettes Institute, 232 Bd Sainte Marguerite, Marseille 13009, France; ${ }^{3}$ Department of Radiotherapy, Paoli-Calmettes Institute, 232 Bd Sainte Marguerite, Marseille 13009, France; ${ }^{4}$ Department of Radiology, Paoli-Calmettes Institute, 232 Bd Sainte Marguerite, Marseille 13009, France; ${ }^{5}$ Department of Anatomopathology, Paoli-Calmettes Institute, 232 Bd Sainte Marguerite, Marseille 13009, France and ' Unité de Recherche Contre le Cancer, CRCM-INSERM U1068, Faculté de Luminy, Université Aix-Marseille, Marseille 13009, France

Background: Sunitinib is a tyrosine kinase inhibitor approved for the treatment of renal cell carcinoma (RCC). Few data evaluated severe buccodental adverse events. The aim of this study was to evaluate sunitinib buccodental toxicity in patients with metastatic RCC and to compare it with that of standard chemotherapy in patients with other solid cancers.

Methods: Patients with RCC treated with sunitinib and patients with other solid tumours treated with chemotherapy were followed for 3 months. Data on dental appliances, oral hygiene/care practices before and during treatment were collected.

Results: A total of 116 patients were included (58 RCC treated by sunitinib: group S, and 58 treated by chemotherapy: group C). No differences in dental care habits were noted before treatment. In group $S$, patients reported significantly more frequent pain $(P<0.01)$, teeth instability $(P=0.01)$, gingival bleeding $(P=0.01)$ and change in teeth colour $(P=0.02)$. In all, $58 \%$ of patients in this group had to modify their diet $(P<0.01)$. Frequency of dentist' visits for teeth removal was increased $(25 \%$ vs $8 \%, P=0.01)$.

Conclusion: Sunitinib seems to increase buccodental toxicity as compared with chemotherapy. This finding emphasises the need for optimal dental care and standardised dental follow-up in patients treated with sunitinib.

Sunitinib is an inhibitor of tyrosine kinases receptors (TKIs), including vascular endothelial growth factor receptors type 1 and 2 , platelet-derived growth factor receptors (PDGFR- $\alpha$ and PDGFR- $\beta$ ), stem cell factor (c-KIT), FMS-like tyrosine kinase 3, colonystimulating factor1 and RET (Mendel et al, 2003; Arora and Scholar, 2005; Chow and Eckhardt, 2007; Haas and Uzzo, 2007). Sunitinib was approved for the treatment of metastatic renal cell carcinoma (mRCC) and metastatic neuroendocrine tumours of the pancreas. The most common toxicities are diarrhoea and fatigue, but other adverse events have also been reported, including stomatitis, hand foot syndrome and hypertension, while long-term side effects are still under investigation (Wolter et al, 2007;
Roodhart et al, 2008; Suwattee et al, 2008). Recently, one case of sunitinib-related osteonecrosis of the jaw (ONJ), has been published in a patient who did not receive any bisphosphonate medication (Ayllon et al, 2009; Brunello et al, 2009). This kind of side effect becomes more common with other TKI and may suggest a specific buccodental toxicity of sunitinib (or antiangiogenics in general). Then we decided to investigate this question. For this purpose, we compared prospectively the type and frequency of buccodental side effects and their functional impact on daily life in patients treated with sunitinib for mRCC with those reported by patients treated with conventional chemotherapy for other malignancies.

\footnotetext{
*Correspondence: Dr G Gravis; E-mail: gravisg@ipc.unicancer.fr
}

Received 3 June 2013; revised 6 August 2013; accepted 9 August 2013; published online 17 September 2013 


\section{PATIENTS AND METHODS}

The authors received approval of the local IRB and all patients gave written informed consent before the study. Each group of patient received clear information about the study and agreed to fill a selfadministered questionnaire, based on 35 questions assessing buccodental status and oral hygiene/care. The questionnaire was designed by medical oncologists and dentists.

The questions included descriptive demographic criteria, such as age, sex, old or recent tobacco intoxication (heavy or former smokers) with number of cigarettes per day since $\mathrm{x}$ year and/or alcohol intoxication, and clinical criteria, such as site of the primary tumour, antitumour treatment duration, number of therapeutic settings and prior treatment by bevacizumab or sorafenib. Concomitant treatment with bisphosphonates and presence of calcium metabolism disorders were also documented. The rest of the questionnaire included questions before treatment: dental status, dental care, frequency of daily tooth brushing and during or after the end of treatment such as dental status, diet changes, pain, dental instability, eating difficulties, cold or sugar sensitivities, gingival bleeding, extraction, cavities, infections, treatment by antibiotics, number of visits to dentists and impact on daily life. These last 14 criteria are defined to secondary buccodental toxicities.

The questionnaire was completed only one time during a consultation visit.

Patients included in the group sunitinib (group S) were seen in outpatients, treated for $\mathrm{mRCC}$, having already received or are being treated by sunitinib. Sunitinib was given at $50 \mathrm{mg} \mathrm{day}^{-1}$ during 4 weeks, followed by a 2-week treatment-free interval. Exclusion criteria were patients unable to understand or complete the questionnaire alone, or non-autonomous.

Patients included in the group chemotherapy (group C) were patients taken randomly, also seen in outpatient in order to have the same performance status between the two groups, treated for metastatic solid cancer in first- or second-line chemotherapy. Chemotherapy was given every week, every 15 days or every 3 weeks in function of protocols. The main drugs that patients received in this group were anthracyclines, taxanes, fluorouracil, platines and gemcitabine. Exclusion criteria were patients unable to understand or complete the questionnaire alone, non-metastatic or non-autonomous.

During the study, clinical examination and biological analyses were performed every 4 weeks for patients in group S and every 3 weeks for patients in group C.

Statistical analysis. To compare the groups, we took consecutive patients treated or been treated with sunitinib at our Institute and took the same number of patients treated by conventional chemotherapies. The hypotheses were expecting to show greater toxicity of $>25 \%$ with sunitinib. Statistical analyses were performed using the Statistical Package for Social Services (SPSS) for Windows Release 10.0 (SPSS, Inc., IBM, Chicago, IL, USA). $T$-tests and Pearson's $\chi^{2}$ analyses with an alpha risk set at 0.05 were performed to compare each group.

\section{RESULTS}

Patients' characteristics. Between October and December 2011, 116 patients treated at the Paoli-Calmettes Institute, Marseille, France, were included in the study (58 in each group). Their characteristics are depicted in Table 1 . Median age was 64 years $(35-80)$ in group S and 63 years (28-84) in group C. In all, $80 \%$ of the patients had a good performance status (Karnofsky score above $80 \%)$ and all were treated on a outpatient basis. There was a significant male predominance in group $\mathrm{S}$ as compared with group C (43 males out of 58 vs 25 males out of 58, respectively, $P=0.05$ ).

Disease and treatment characteristics. Median duration of treatment was 22 months (2-62) and 19 months (1-135) for sunitinib and chemotherapy, respectively, $(P=0.18)$. All patients

\begin{tabular}{|c|c|c|c|}
\hline & Group S $(n=58)$ & Group C $(n=58)$ & $\boldsymbol{P}$-value \\
\hline Age, years median (range) & $64(35-80)$ & $63(28-84)$ & 0.16 \\
\hline Sex: male/female $(n)$ & $43 / 15$ & $25 / 33$ & 0.05 \\
\hline Karnofsky score \% (median (range) & $80(60-100)$ & $80(50-100)$ & 0.07 \\
\hline History of smoking, $n(\%)$ & $5(8.6 \%)$ & $13(22 \%)$ & 0.02 \\
\hline Tumour site, $n(\%)$ & Kidney $=58$ (100\%) & $\begin{array}{c}\text { Colorectal = } 20(34 \%) \\
\text { Ovarian }=11(21 \%) \\
\text { Breast }=9(15 \%) \\
\text { Pancreas }=8(13 \%) \\
\text { Other }=10(16 \%)\end{array}$ & \\
\hline Median duration of antitumoural treatment, months (range) & $22(2-62)$ & $19(1-135)$ & 0.18 \\
\hline \multicolumn{4}{|l|}{ Treatment by bisphosphonates } \\
\hline $\begin{array}{l}\text { Yes } \\
\text { Median duration of treatment, months (range) }\end{array}$ & $\begin{array}{c}9(15.5 \%) \\
16.8(3-18)\end{array}$ & $\begin{array}{c}7(12 \%) \\
16.2(2-18)\end{array}$ & $\begin{array}{l}0.16 \\
0.7\end{array}$ \\
\hline Treatment by bevacizumab before sunitinib or during chemotherapy, $n$ (\%) & 9 (15.5\%) & $8(13.7 \%)$ & 0.12 \\
\hline Prior treatment by sorafenib & $5(8.6 \%)$ & $0(0 \%)$ & 0.01 \\
\hline \multicolumn{4}{|l|}{ Number of lines in the metastatic setting } \\
\hline $\begin{array}{l}1 \\
2 \\
3 \text { or more }\end{array}$ & $\begin{array}{c}53(91.4 \%) \\
5(8.6 \%) \\
0\end{array}$ & $\begin{array}{l}22(38 \%) \\
26(44 \%) \\
10(18 \%)\end{array}$ & 0.001 \\
\hline
\end{tabular}


had metastatic diseases. Bisphosphonates were administered for hypercalcaemia or bone metastasis, in $15.5 \%$ and $12 \%$ of patients in groups $\mathrm{S}$ and $\mathrm{C}$, respectively, $(P=0.16)$, with a median duration of 16 months in both groups $(P=0.7)$. In group $S$, only five patients $(8.6 \%)$ were on a second-line metastatic treatment and have been previously treated by sorafenib, the other patients being treated frontline. In group $\mathrm{C}$, the most frequently used chemotherapies were anthracyclines, taxanes and fluorouracil while $38 \%$ of patients being treated for a first metastatic treatment, $44 \%$ for second metastatic course and $18 \%$ for third and above metastatic course, respectively. Nine and eight patients received antiangiogenic treatment by bevacizumab in groups $S$ and $C$, respectively, $(P=0.12)$.

Pre-treatment dental status and care. Pre-treatment buccodental status was average or bad for 30 patients in both groups $(P=0.2)$. Patients had similar pre-treatment buccodental care (dental adhesive care: $18 \%$ and $17 \%$ in groups $S$ and $C$, respectively, $(P=0.13)$, dental prosthesis: four patients $(6.9 \%)$ in both groups $(P=0.8)$ and frequency of daily tooth brushing). However, frequency of dentist's visits were different with significantly more patients in group $S$ visiting their dentist less than once a year $(58 \%$ vs $49 \%, P=0.01$; Table 2 ).

Buccodental toxicity during treatment. Patients' self-reports of dental and gingival toxicities during oncologic treatment are reported in Table 3. The following adverse events were reported with a significantly higher frequency in group $S$ : teeth colour changes $(P=0.02)$, pain $(P<0.01)$, teeth instability $(P=0.01)$ and gingival bleeding $(P=0.01)$. More than $50 \%$ of patients in this group had to change their dietary habits $(58 \%$ vs $25 \%, P<0.001)$ because of buccodental side effects. However, neither cold nor sugar sensitivity were significantly increased. The periodontal/ gingival alterations translated into a higher frequency of dentists' visits within the few months following treatment initiation (39\% vs $32 \%, P=0.04)$, in order to receive antibiotics $(25 \%$ vs $10 \%$, $P=0.01)$, to undergo teeth extraction $(25 \% v s 8 \%, P=0.01)$ or to set up of a denture $(15 \%$ vs $0 \%, P<0.001)$.

In each group, patients with a pre-treatment defective hygiene seem to present more complications than the others (data not shown) but no significant differences between the two groups were

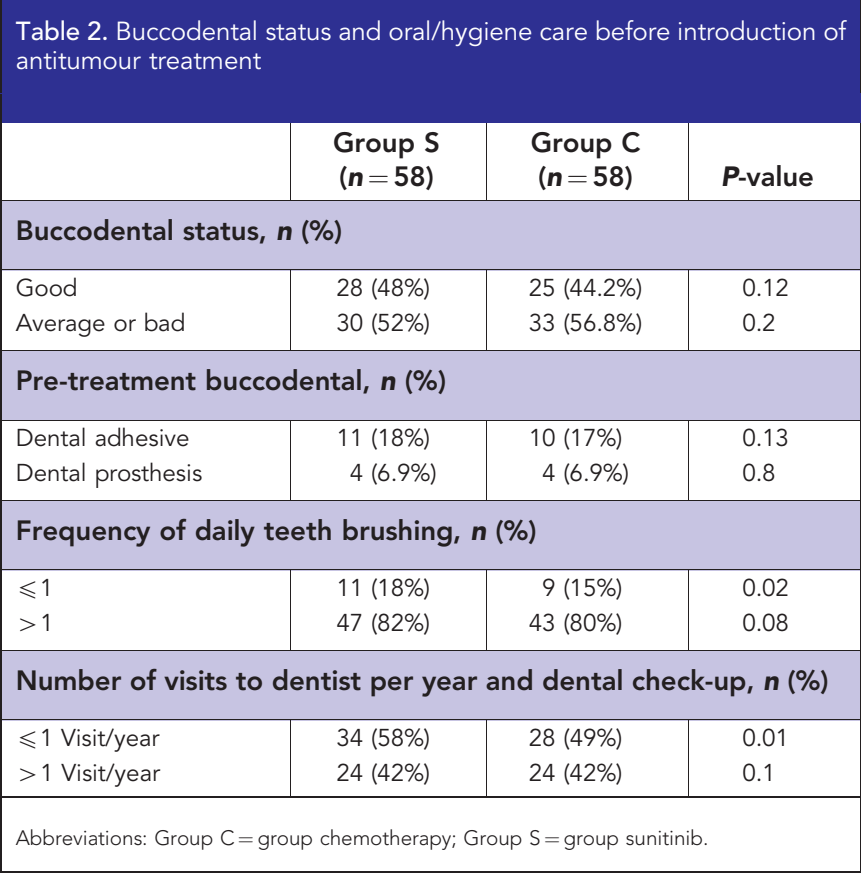

found regarding general buccodental status assessment, frequency of tooth brushing, incidence of cavities. Moreover, no significant differences were observed in terms of functional impact in daily life between the two groups $(P=0.81)$.

Statistical analyses were repeated exclusion of patients treated with bisphosphonates, and no significant changes in terms of differences were observed.

Smoking habits and oral lesions. A history of smoking was reported by $8.6 \%$ and $22 \%$ of patients in groups $\mathrm{S}$ and $\mathrm{C}$, respectively, $(P=0.02)$. Patients with poor hygienic habits and tobacco or alcohol exposure presented more dental complications, such as cavities and loosening teeth (data not shown).

\section{DISCUSSION}

As cancer treatment becomes more intense and prolonged, deleterious effects on normal tissues may increase. The effective management of expected side effects associated with anticancer therapy is a key point in patients' global care. Buccodental toxicities are poorly known or reported for most anticancer therapies including targeted therapies (National Institutes of Health, 1989). Such toxicities may limit food intake, impair patient's quality of life and finally, represent an efficacy-limiting factor (Zadik et al, 2010). Over the past 10 years, many studies focused on oropharyngal mucositis (Elting et al, 2003; Lalla et al, 2008; Peterson et al, 2009) but data on treatment-related buccodental effects are limited. Toxicity in oral status could influence diet and patient's nutrition, especially in elderly patients. Moreover, pain associated with these complications may result in dose reduction, which is often associated with increased cancer recurrence and decreased survival rates (Rosenthal, 2007).

Table 3. Comparison of the frequencies of dental and gingival toxicities between group $S$ and group $C$ during treatment

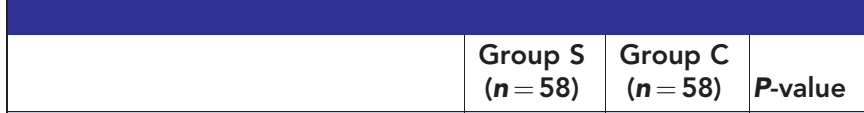

Frequency of daily teeth brushing, $n(\%)$

\begin{tabular}{|l|l|l|l|}
\hline$\leqslant 1$ & $11(18 \%)$ & $12(20 \%)$ & 0.06 \\
$>1$ & $47(81 \%)$ & $46(79 \%)$ & 0.09 \\
\hline
\end{tabular}

Buccodental status, $\boldsymbol{n}(\%)$

\begin{tabular}{|l|l|l|l}
\hline Good & $18(31 \%)$ & $17(29 \%)$ & 0.20
\end{tabular}

Average or bad

Teeth colour changes, $n(\%)$

Pain, $n$ (\%)

Teeth instability, $n$ (\%)

Loosening of the teeth, $n(\%)$

Eating difficulties, $n$ (\%)

Gingival cold sensitivity, n (\%)

Gingival sugar sensitivity, $n(\%)$

Gingival bleeding, $n$ (\%)

Diet changes, $n$ (\%)

More visits to dentists, $n(\%)$

Teeth extraction during treatment, $n(\%)$

Denture set-up, n (\%)

Cavities, $n$ (\%)

Antibiotics during treatment, $n(\%)$

$40(69 \%)$

$23(39 \%)$

41 (70\%)

20 (34\%)

37 (63\%) $\quad 23(39 \%)$

$25(43 \%) \quad 14(24 \%)$

$21(36 \%) \quad 20(38 \%)$

$34(58 \%) \quad 15(26 \%)$

$31(53 \%) \quad 29(50 \%)$

$11(18 \%) \quad 10(18 \%)$

$36(62 \%) \quad 23(39 \%)$

34 (58\%) 15 (25\%)

$23(39 \%) \quad 19$ (32\%)

$15(25 \%) \quad 5(8 \%)$

$9(15 \%) \quad 0(0 \%)$

$10(17 \%) \quad 10(17 \%)$

$15(25 \%)$

$6(10 \%)$

0.40

0.02

$<0.01$

0.01

0.68

0.04

0.09

0.75

0.01

$<0.01$

0.04

0.01

$<0.01$

0.2

0.01

Quality of life impairment, $n$ (\%)

\begin{tabular}{|l|l|l|l|}
\hline Yes & $33(57 \%)$ & $34(59 \%)$ & 0.84 \\
\hline
\end{tabular}

Abbreviations: Group $\mathrm{C}=$ group chemotherapy; Group $\mathrm{S}=$ group sunitinib. 
The multiple toxicities of cancer therapy in general has become increasingly apparent and led to develop the concept of a 'symptom burden' for a given patient, in which both severity of symptoms and patient's perception of their impact are relevant (Cleeland, 2007). The risk of developing buccodental toxicities is determined by a complex set of interactions with a variety of factors (type of malignancy, prescribed forms of therapy, age, status of oral health, nutritional status and so on) as described in the literature (Heimdahl and Nord, 1990; Sonis and Fey, 2002).

Commonly reported toxicities for antiangiogenic agents in patients with mRCC include asthenia, diarrhoea, nausea, anorexia, rash, hypertension, myelosuppression, elevated levels of thyroidstimulating hormone, hypothyroidism and hepatotoxicity including liver failure (Rini, 2009; Di Lorenzo et al, 2011). Across oncology trials with sunitinib, these toxicities occur in $\geqslant 20 \%$ of patients (Motzer et al, 2009) but only few studies described oral toxicities, with the exception of the recent case report of ONJ by Fleissig et al (2012). In the literature, it has been suggested that unadapted dentures and exposure to alcohol and tobacco may create the oral mucosa and may favour the risk of chemotherapy-induced oral mucositis (Sonis and Clark, 1993; Christoloudou et al, 2009). In our study, only few patients had chronic alcoholic exposure, but $8 \%$ in group S and $22 \%$ in group C were heavy smokers or had prior tobacco exposure. Surprisingly, the percentage of smokers in group $\mathrm{S}$ was lower than of group $\mathrm{C}$, while it was expected to be higher.

Moreover, we could note that denture set up was more frequent in group S but this may be confounded (by indication) by the fact that subjects in group $S$ more frequently visited their dentist at baseline. However, during treatment, difference was not significant between the two groups.

Some patients $(15 \%)$ received bisphosphonates, a treatment known to be responsible for ONJ (Woo et al, 2006; Christoloudou et al, 2009). Although there is just one case of ONJ described with sunitinib (Fleissig et al, 2012), the recent case of bevacizumabrelated ONJ suggests that antiangiogenic therapy may contribute to oral mucosal lesions or impair angiogenesis-dependent bone cell differentiation and formation (Estilo et al, 2008; Santos-Silva et al, 2013). By inhibiting growth factor receptors and affecting revascularisation, sunitinib could have been responsible for osteonecrosis and poor wound healing after tooth extraction (Roodhart et al, 2008). This could explain the differences in oral toxicities between the two groups, in particular pain, fall of the teeth and need to denture set up.

In our study, the challenge for the long survivors was to find conceptual issues to anticipate symptoms in order to preserve a correct dental capital as well as it has been proposed in the past (Miaskowski et al, 2007; Aprile et al, 2008). It has been suggested that patients should visit their dentist for evaluation and care before starting chemotherapy as well as during treatment, but this approach is not systematic. According to our results, the same recommendations should apply to patients who receive sunitinib, but further prospective studies are needed to identify patients at risk of buccodental toxicity and to describe more accurately the type of dental follow-up to be performed, based on the patient's dental status.

In our study, dental or parodontal lesions were more frequently observed in the group treated by sunitinib, suggesting first, that patients should be specifically informed about these side effects, in order to prevent them as far as possible. This information should be simple, adapted and reassuring, but should focus on symptoms indicating a serious side effect. The message can be emphasised by nurse consultation, transmission to patients of the individualised care plan or linkage notebook, such as other oral chemotherapies (capecitabine, imatinib). Comprehensive clinical examination (global health status, nutritional status and buccodental status) and review of relevant pathological, radiological and biological data should be performed before any chemotherapy/targeted therapy prescription. As one could notice in our study, patients with a defective hygiene seem to present more complications than the others whatever pre-treatment dental care done. This should encourage us to develop patient's information and prescription of prophylactic supportive care, such as mouthwashes, tooth brushing and appropriate diet. As nutritional status may have an impact on the incidence of buccodental side effects, nutritional biological parameters should be measured and taken into account. Other biological parameters currently under investigation may become important in the future: Van Erp et al (2009) demonstrated that the risk for mucosal inflammation was increased in the presence of $\mathrm{G}$ allele in CYP1A1 2455A/G in patients receiving single-agent sunitinib. These findings are particularly noteworthy and could lead to genetic-based technology to analyse toxicity associated with a molecularly targeted cancer therapy.

Then, strategies could be subsequently developed and tested, such as, prescription of panoramic X-rays as far as necessary, for screening of periapical lesions of granuloma, infections or first occurrence of osseous lesions. This is very important because buccodental lesions can be responsible for very serious complications, such as ONJ, sepsis and infectious endocarditis. For all patients, and especially for elderly patients, life expectancy, comorbidities, level of dependency and comprehensive geriatric assessment should be taken into account before initiation of treatment and during follow-up.

In summary, this prospective study highlighted the frequency of buccodental side effects among sunitinib-treated patients, and stressed the need for adapted information, prevention and surveillance. The purpose of the study was to demonstrate the fact that mouth and dental examination is not really a systematic assessment in the follow-up of these patients but, should be, considering its major importance and role for the long-term side effect occurrences. Moreover, considering the long-term benefits of sunitinib exposure in mRCC patients, our study pleads for optimised supportive care (including oral pain control, nutritional support and prevention/treatment of infections) for patients experiencing buccodental side effects, in order to favour compliance to treatment.

More studies are needed to address the complex relationship among pathobiological mechanisms, risks for clinically relevant side effects, and response to preventive and therapeutic interventions. It is likely that further research on mucositis and oral lesions will allow predicting the risk of toxicity and develop customised prophylactic and therapeutic approaches. These advances could mark a new era in the management of oral injuries caused by cancer therapies.

\section{ACKNOWLEDGEMENTS}

We thank all the patients who have accepted to be included in the study. We thank Anne Visbecq for assistance in the preparation of the manuscript.

\section{CONFLICT OF INTEREST}

The authors declare no conflict of interest.

\section{REFERENCES}

Aprile G, Ramoni M, Keefe D, Sonis S (2008) Application of distance matrices to define associations between acute toxicities in colorectal cancer patients receiving chemotherapy. Cancer 112: 284-292. 
Arora A, Scholar EM (2005) Role of tyrosine kinase inhibitors in cancer therapy. J Pharmacol Exp Ther 315: 971-979.

Ayllon J, Launay-Vacher V, Medioni J, Cros C, Spano JP, Oudard S (2009) Osteonecrosis of the jaw under bisphosphonate and antiangiogenic therapies: cumulative toxicity profile? Ann Oncol 20: 600-601.

Brunello A, Saia G, Bedogni A, Scaglione D, Basso U (2009) Worsening of osteonecrosis of the jaw during treatment with sunitinib in a patient with metastatic renal cell carcinoma. Bone 44: 173-175.

Chow LQ, Eckhardt SG (2007) Sunitinib: from rational design to clinical efficacy. J Clin Oncol 25: 884-896.

Christodoulou C, Pervena A, Klouvas G, Galani E, Falagas ME, Tsakalos G, Visvikis A, Nikolakopoulou A, Acholos V, Karapanagiotidis G, Batziou E Skarlos DV (2009) Combination of bisphosphonates and antiangiogenic factors induces osteonecrosis of the jaw more frequently than bisphosphonates alone. Oncology 76: 209-211.

Cleeland CS (2007) Symptom burden: multiple symptoms and their impact as patient-reported outcomes. J Natl Cancer Inst Monogr 37: 16-21.

Di Lorenzo G, Porta C, Bellmunt J, Sternberg CN, Kirkali Z, Staehler M, Jomiau S, Montorsi F, Buonerba C (2011) Toxicities of targeted therapy and their management in kidney cancer. Eur Urol 59: 526-540.

Elting LS, Cooksley C, Chambers M, Cantor SB, Manzullo E, Rubenstein EB (2003) The burdens of cancer therapy. Clinical and economic outcomes of chemotherapy-induced mucositis. Cancer 98(7): 1531-1539.

Estilo CL, Fornier M, Farooki A, Carlson D, Bohle 3 rd G, Huryn JM (2008) Osteonecrosis of the jaw related to bevacizumab. J Clin Oncol 26(24): 4037-4038.

Fleissig Y, Regev E, Lehman H (2012) Sunitinib related osteonecrosis of jaw: a case report. Oral Surg Oral Med Oral Pathol Oral Radiol 113(3): e1-e3.

Haas NB, Uzzo RG (2007) Tyrosine kinase inhibitors and antiangiogenic therapies in kidney cancer. Curr Treat Options Oncol 8: 211-226.

Heimdahl A, Nord CE (1990) Oral infections in immunocompromised patients. J Clin Periodontal 17: 501-503.

Lalla RV, Sonis ST, Peterson DE (2008) Management of oral mucositis in patients who have cancer. Dent Clin North Am 52: 61-77.

Mendel DB, Laird AD, Xin X, Louie SG, Christensen JG, Li G, Schreck RE, Abrams TJ, Ngai TJ, Lee LB, Murray LJ, Carver J, Chan E, Moss KG, Haznedar JO, Sukbuntherng J, Blake RA, Sun L, Tang C, Miller T, Shirazian S, McMahon G, Cherrington JM (2003) In vivo antitumor activity of SU11248, a novel tyrosine kinase inhibitor targeting vascular endothelial growth factor and platelet-derived growth factor receptors: determination of a pharmacokinetic/pharmacodynamic relationship. Clin Cancer Res 9: 327-337.

Miaskowski C, Aouizerat BE, Dodd M, Cooper B (2007) Conceptual issues in symptom clusters research and their implications for quality-of-life assessment in patients with cancer. J Natl Cancer Inst Monogr 37: 39-46.

Motzer RJ, Hutson TE, Tomczak P, Michaelson MD, Bukowski RM, Oudard S, Negrier S, Szczylik C, Pili R, Bjarnason GA, Garcia-del-Muro X, Sosman JA, Solska E, Wilding G, Thompson JA, Kim ST, Chen I, Huang X, Figlin RA (2009) Overall survival and updated results for sunitinib compared with interferon alfa in patients with metastatic renal cell carcinoma. J Clin Oncol 27: 3584-3590.

National Institutes of Health (1989) Consensus Development Conference Statement on Oral Complications of Cancer Therapies: Diagnosis, Prevention, and Treatment. 7 April.

Peterson DE, Barker NP, Akhmadullina LI, Rodionova I, Sherman NZ, Davidenko IS, Rakovskaya GN, Gotovkin EA, Shinkarev SA, Kopp MV, Kulikov EP, Moiseyenko VM, Gertner JM, Firsov I, Tuleneva T, Yarosh A, Woon CW (2009) Phase II, randomized, double-blind, placebo-controlled study of recombinant human intestinal trefoil factor oral spray for prevention of oral mucositis in patients with colorectal cancer who are receiving fluorouracil-based chemotherapy. J Clin Oncol 27: 4333-4338.

Rini BI (2009) Vascular endothelial growth factor-targeted therapy in metastatic renal cell carcinoma. Cancer 115: 2306-2312.

Roodhart JM, Langenberg MH, Witteveen E, Voest EE (2008) The molecular basis of class side effects due to treatment with inhibitors of the VEGF/ VEGFR pathway. Curr Clin Pharmacol 3: 132-143.

Rosenthal DI (2007) Consequences of mucositis-induced treatment breaks and dose reductions on head and neck cancer treatment outcomes. $J$ Support Oncol 5: 23-31.

Santos-Silva AR, Belizário Rosa GA, Castro Júnior Gd, Dias RB, Prado Ribeiro AC, Brandão TB (2013) Osteonecrosis of the mandible associated with bevacizumab therapy. Oral Surg Oral Med Oral Pathol Oral Radiol 115(6): 32-36.

Sonis ST, Clark J (1993) Prevention and management of oral mucositis induced by antineoplastic therapy. Oncology 5: 11-18.

Sonis ST, Fey EG (2002) Oral complications of cancer therapy. Oncology 16(5): 680-686.

Suwattee P, Chow S, Berg BC, Warshaw EM (2008) Sunitinib: a cause of bullous palmoplantar erythrodysesthesia, periungual erythema, and mucositis. Arch Dermatol 144: 123-125.

Van Erp NP, Eechoute K, van der Veldt AA, Haanen JB, Reyners AK, Mathijssen RH, Boven E, van der Straaten T, Baak-Pablo RF, Wessels JA, Guchelaar HJ, Gelderblom H (2009) Pharmacogenetic pathway analysis for determination of sunitinib-induced toxicity. J Clin Oncol 27: 4406-4412.

Wolter P, Dumez H, Schoffski P (2007) Sunitinib and hypothyroidism. N Engl J Med 356: 1580.

Woo SB, Hellstein JW, Kalmar JR (2006) Narrative review: BPs and osteonecrosis of the jaws. Ann Intern Med 144(10): 753-761.

Zadik Y, Vainstein V, Heling I, Neuman T, Drucker S, Elad S (2010) Cytotoxic chemotherapy-induced odontalgia: a differential diagnosis for dental pain. J Endod 36(9): 1588-1592.

This work is published under the standard license to publish agreement. After 12 months the work will become freely available and the license terms will switch to a Creative Commons AttributionNonCommercial-Share Alike 3.0 Unported License. 